\title{
Physicochemical and microorganism analysis of some hand pump water in Pelengana, Segou, Mali
}

\author{
Amadou Toure $^{1,2} \cdot$ Duan Wenbiao $^{1}$
}

Received: 20 August 2018 / Accepted: 6 May 2020 / Published online: 26 May 2020

(c) The Author(s) 2020

\begin{abstract}
Groundwater from hand pump could be a principal supply of potable in the large part of rural areas of Mali. Indeed, it was found that this source was the safest to meet water request in remote areas (i.e., rural) of the low-income countries like Mali. However, groundwater quality is changed once external substances are available to contact with the water table. An evaluation of physicochemical and microbial qualities of hand pump water in the rural commune of Pelengana, Mali, was performed. The parameters analyzed include: physical (temperature, $\mathrm{pH}$, and turbidity), chemical (nitrate, and phosphate) and microbiological (both fecal and total coliform bacteria), using standard procedures of analysis. Moreover, API 20E test was used to determine the identities of isolates. Findings have been compared with the WHO drinking water guidelines (or other) values. All physicochemical parameters in hand pump water samples were within the limit recommended by the WHO guideline (or other) values except to turbidity, and nitrate, whereas microbial concentrations during the rainy season were above the WHO acceptable limits. The presence of species such as Escherichia coli, Salmonella and Klebsiella in hand pump waters suggests that water from these sources constitute a threat to public health and is inappropriate for drinking without treatment.
\end{abstract}

Keywords Hand pump waters $\cdot$ Bacteria isolates $\cdot$ Microbial $\cdot$ Physicochemical $\cdot$ Water quality

\section{Introduction}

Water is a renewable resource permanently threatened by pollution, among others, of demographic, agricultural and industrial origins. Access to safe water may be a requirement for health, a basic right and a key element of effective health protection policies. However, groundwater accounts for the safest and significant source supply of drinking water in the world (Palamuleni and Mercy 2015). Roughly 1.5 billion people in all over the world are daily provided in drinking water through the groundwater (Iyasele and Idiata 2012). Indeed, it was found that this source was the foremost reliable for responding to water request in rural areas of the

Duan Wenbiao

dwbiao88@126.com

Amadou Toure

touamare03@yahoo.fr

1 School of Forestry, Northeast Forestry University, No. 26 Hexing Road Xiangfang District, Harbin 150040, People's Republic of China

2 Department of Chemical, Faculty of Sciences and Technologies of Bamako, Bamako, Mali low-income countries (i.e., in sub-Saharan Africa) (Harvey 2004). Owing to the incapacity of decision-makers to retort to the ever-growing need for water, the populace, especially in the remote, resorts to sourcing water from groundwater such as hand pump. Thus, groundwater's is the resources of water used by human being for a variety of purposes, namely for industrial, farming and domestic (Prasad and Narayana 2004). Nevertheless, groundwater quality will be changed once external substances are available to contact with the geological formation (i.e., aquifer). Unwanted stuff renders groundwater inappropriate for numerous utilizations, particularly for drinking need.

Usually, chemical composition natural groundwater varies according to the places. This could be due not only to seasonal variability, however, additionally to the geologic nature of the soil from which have its origin and additionally the reactive stuffs it would be faced with throughout flow (Thivya et al. 2014; Seth et al. 2014). It is value to notice that contaminants are naturally present in the source rocks on which soils develop. Indeed, whether these rocks are of magmatic or sedimentary origin, whether they are acidic or basic, contain at different levels of metals. As a result, through flow, metals are naturally present in groundwater 
and their concentrations depend on the rocks and sediments type (Moyo 2013). Moreover, thoroughgoing utilization of natural resources and accumulated activities of anthropic origin can cause grave groundwater quality problems due to the removal or spread of chemical substances and microbial communities on the surface of the soil and into soils or by the direct intrusion of waste into the water table (Mor et al. 2006). Residue from fecal peril, agricultural fertilizer, and allied products, as well as industrial discharges, are potential contaminant agents. They may accrue and move toward groundwater, influencing the physical, chemical and bacteriological quality of the water (Sabhapandit and Saikia 2010).

In developing countries, particularly in rural Africa, the traditional pit latrine is the most commonly used type of sanitation for the majority of households, which is not without an impact on the microbial quality of groundwater. It is well-known that a sewage-disposal tank may bring about microorganisms into the groundwater. Also, if agricultural manures do not seem to be absorbed by plants, it penetrates into the underground and finds yourself within the water drawn from a hand pump (Tamme et al. 2009). The poor sanitary condition during hand pumps construction may conduct the contamination of groundwater. Flooding at the sites, the closeness of certain hand pump to rubbish dumps and livestock manure strewed near those pumps may evenly alter the nature of groundwater (Bello et al. 2013). Hence, the bacteriological and physicochemical quality of groundwater requires constant assessment both in the developed and underdeveloped countries (Healy et al. 2014). So as to preserve the long-term sustainability of water resources (groundwater), it is necessary to control water quality permanently (Raihan and Alam 2008).

Segou, the capital city of the Segou Region within the center of Mali, is one among many cities in Mali whose populace particularly in remote zones is largely dependent on hand pumps water, dug wells water and boreholes water. The larger part of the surrounding peri-urban zones notably Pelengana commune is not connected to the drinking water network. Over $70 \%$ of the populace of Pelengana commune is currently supplied with water by hand pumps (CPS/MS $\&$ DNSI 2006). Despite the fact that bacterial contamination could also be a number one concern in the commune of Pelengana, inorganic contaminants and health risks are additionally pose a risk to water from these sources. Inhabits of that space follow agro-pastoralism. Pesticides, microbial substances and chemical fertilizers based on nitrates and phosphates are typically used to obtain a good agricultural yield and, in most cases, they exceed the recommended dosages. Whether all of the nitrates are not entirely immersed by plant roots, it will seep into the soil or drain toward water reservoirs during humidification or downfall (Tamme et al. 2009). Utilization of polluted groundwater or crops containing high levels of nitrates has harmful results on human health (Ikemoto et al. 2002). In addition, water sources are liable to be affected by high levels of salinity and hardness. Obviously, drinking water having various trace elements (i.e., $\mathrm{Cd}, \mathrm{Pb}, \mathrm{As}, \mathrm{Cr}, \mathrm{Hg}$, etc.) has significant negative effects on human health, due to extreme consumption. Besides, those trace elements are also dangerous to human health as they are toxic and may be carcinogenic. Water quality issues have in part been linked with inappropriate sanitation (Palamuleni and Mercy 2015).

Overall, the great majority of households in the rural area of Pelengana commune use the traditional pit latrine. However, it absolutely was detected that the drinking water sources in certain localities are more or less among a thirty $m$ or less radius from pit latrines, refuse tips and other social amenities, which accentuates a hazard of contamination of the water table which provides the village. Moreover, there are not any information elaborate offered with relevance the water quality as well as the dominant water-associated diseases within the commune of Pelengana. It is thus this context, that the physical, chemical and bacteriologic parameters of hand pump water in Pelengana commune were evaluated in order to determine if the hand pump water has complied the allowable limits for human consumption as set by the WHO guideline.

\section{Materials and methods}

\section{Study area and water sampling}

The present study has been done in the Pelengana commune in Segou region of Mali in West Africa (Fig. 1 ). Pelengana commune is found in the south of Mali, at a distance of approximately $235 \mathrm{~km}$ of the capital Bamako. It has a total population estimated at 118,814 inhabitants as of populace and habitat census of 2009. The population density for the commune is estimated at 37.8 inhabitants per $\mathrm{km}^{2}$, with an annual growth rate of $3.1 \%$ (RGPH 2009) and is located between $13^{\circ} 26^{\prime}$ at latitude North and $6^{\circ} 12^{\prime}$ at longitude East. The sudano-sahelian-type climate is marked by the alternation of 2 periods (i.e., 2 seasons): a rainy period from June to September and a longer dry season from October to May. Precipitation is quite low, with an annual mean of up to $625 \mathrm{~mm} /$ year; the highest precipitation is recorded in August. Residents of the different villages of the area practice agro-pastoralism, relying mainly upon agriculture, including millet, groundnut, cotton and vegetables.

The sampling has been achieved during two investigations periods: one in the rainy period (July 2017) and the other in the dry period (March 2017). Among twelve randomly selected hand pump (Hap) in the Pelengana commune, 36 water samples have been collected for physical, chemical and bacteriological analyzes. It is value noting that 

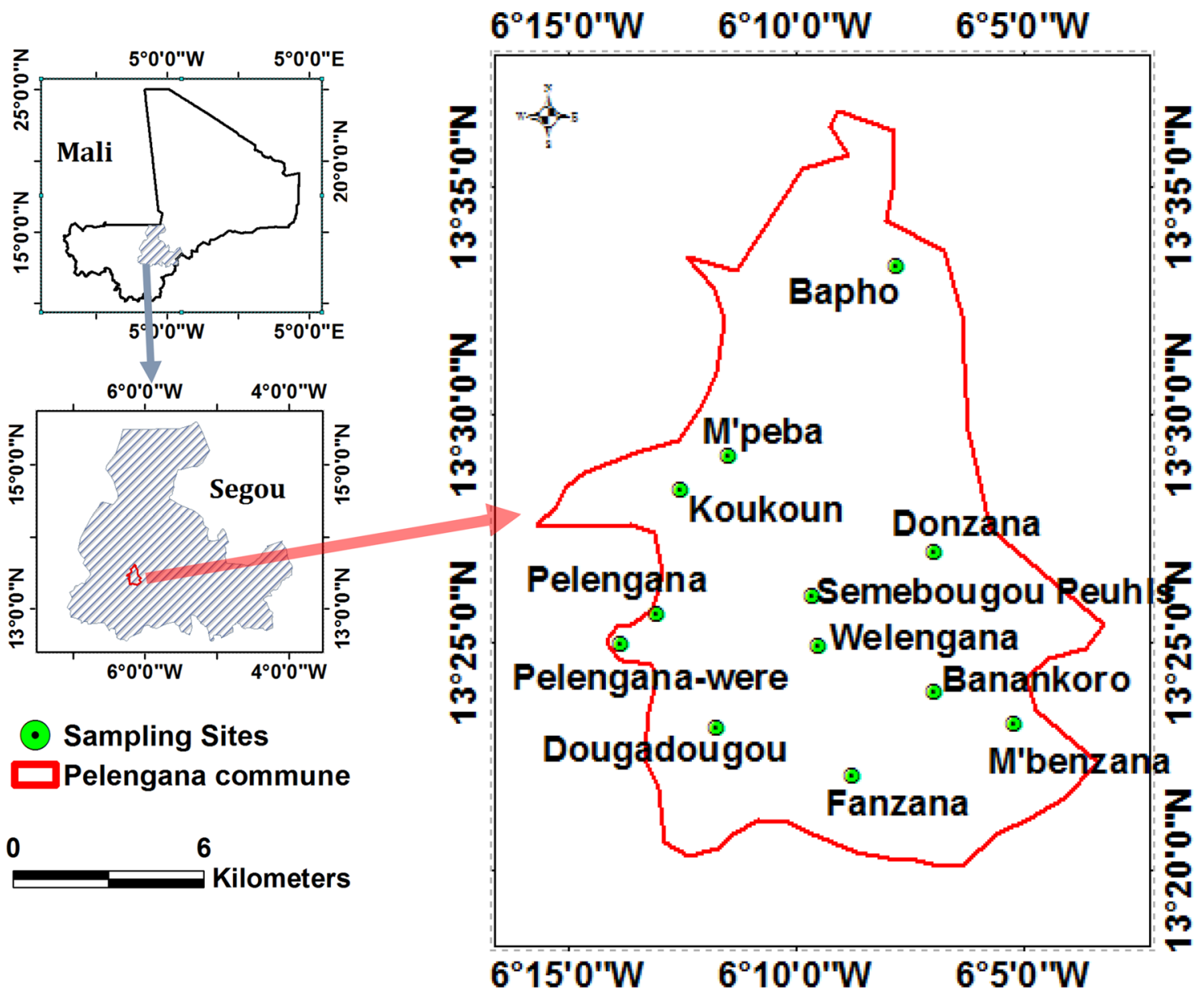

Fig. 1 Map of the study zone in Mali

sampling points remained constant throughout the study. Hand pump water samples were taken after pumping for $10 \mathrm{~min}$, followed by a reduction in the flow of water to allow filling the bottles without splashing. 1L polyethylene bottles were used for water samples' collection. These bottles were firstly washed with non-ionic detergent and rinsed with tap water and distilled water. They were thus rinsed 3 times with water taken from the hand pumps selected. At the same time, samples for microbial analysis have been taken using autoclave-sterilized sample bottles from the same locations. The water samples were fastidiously tagged and kept in a cooler at temperatures ranging from 0 to $4{ }^{\circ} \mathrm{C}$. Finally, they have been delivered to the National Water Laboratory (Laboratoire National des Eaux (LNE)), Bamako, Mali within $6 \mathrm{~h}$ of their collection for further processing.

\section{Analytical procedures}

It is needful to examine the physicochemical and bacteriological quality so as to determine the degree of water pollution regarding the different parameters, and also the hazards to human health related to consumption of water affected by contaminants within the investigate zone. Temperature, $\mathrm{pH}$ and turbidity have been measured in situ employing a digital thermometer, $\mathrm{pH}$ meter WTW (Wissenschaftlich-Technische Werkstätten $\mathrm{GmbH}$ ), and a turbidimeter, respectively. The nitrate and phosphate concentrations were ascertained in the laboratory using ultraviolet spectrophotometer, $\mathrm{HACH}$ 2800, employing standard ethylene diamine tetra-acetic acid (EDTA) as given American Public Health Association (APHA 1992).With regard to bacteriological analyzes, only the specific indicators of environmental and fecal contamination (total coliforms and Escherichia coli) were searched using the membrane filter technique (USEPA 2009). They were enumerated in $50 \mathrm{~mL}$ aliquots of the water sample. In addition, aliquots of each water sample have been filtered using $0.45 \mu \mathrm{m}$ paper filters (Whatman glass fiber filter paper type $934-\mathrm{AH}$ ). So as to detect total coliforms and Escherichia coli, the filter papers have been placed onto $\mathrm{m}-\mathrm{FC}$ and $\mathrm{m}$-ENDO agar followed by incubation at $45-37^{\circ} \mathrm{C}$ for $24 \mathrm{~h}$. Blue and metallic sheen colonies on membrane-fecal coliforms (m-FC) and Endo's medium (m-ENDO) agar plates

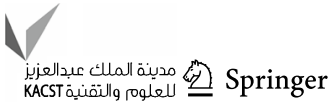


have been filtered and utilized for the microbiological identification assay. The biochemical test such as oxidase, citrate utilization and triple sugar iron tests was performed, and each plate was confirmed and given a positive or negative score. However, isolates were confirmed through biochemical identification tests (EnteroPluri-Test) in order to detect microorganisms belonging to the Enterobacteriaceae group.

\section{Statistical analyses}

The data for quality (physical, chemical and microbial) of water consumption and the state of water contamination are recorded and measured for $\mathrm{pH}$, turbidity, nitrate, phosphate, total coliforms and E. coli. The analyzed results (average, and standard deviations) from the 3 samples per sampling site are calculated and compared with the WHO guideline for drinking water.

\section{Results and discussion}

\section{Physicochemical analyses}

Table 1 summarizes the physical and chemical results obtain in the dry and rainy season in the hand pump water samples of the study area. These results were compared with that of the WHO guidelines values for drinking water quality. In certain cases, no WHO guidelines values, but other values were considered for clarity.

Temperature is one in all the physicochemical parameters considered to assess drinking water quality. It has an impact not only on the living but also nonliving constituents of the environment, consequently affect organisms and the functioning of an ecosystem (Olajire and Imeokparia 2001). The temperature for the collected hand pump water samples varied in line with the sampling season. Overall average values during the rainy and dry season have been $20.6{ }^{\circ} \mathrm{C}$ and $22.14{ }^{\circ} \mathrm{C}$, respectively (Table 1). It is worth noted that there is no health-based guideline, despite the temperature normally influences the water quality, i.e., high water temperature favors the growth of micro-organisms, and consequently taste, odor, color and corrosion issue may increase. The ideal temperature of drinking water is between 6 and $15{ }^{\circ} \mathrm{C}$ as the palatability of water is reinforced by its coolness (Degbey et al. 2011).

The measure of the $\mathrm{pH}$ content is a significant index of acidity or alkalinity. $\mathrm{pH}$ of water has no direct negatives results on the human being, however, rather indirect results due to the fact that it can carry modifies in some parameters of water quality, including the initial chemical form of metals and survival of infectious agents (WHO 2008). Also, it can cause gastrointestinal irritation in sensitive persons (Ho et al. 2003). pH average values for different sites ranged from 6.2 to 7.6 for both seasons, and the highest average value has been seen in the wet season. However, results showed that the $\mathrm{pH}$ of all hand pump water samples collected during both the rainy and dry season are within the acceptable limit recommended by WHO guidelines. As a result, the logarithmic function of hydrogen ion $(\mathrm{pH})$ concentration in this study was appropriate for water for drinking functions.

Water turbidity is highly significant due to that high turbidity values are frequently linked with a higher level of pathogenic microorganisms, including bacteria and other parasites (Shittu et al. 2008). Additionally, turbidity levels reliant on the quantity of suspended particles which find in the water. Moreover, turbidity as such is not perforce a danger for the human being but can to negatively affect the acceptability due to visible cloudiness (WHO 2011). The turbidity average values for all the water samples are confined in the range from 0.7 to 23.2 NTU. Although there is no health-based guideline, turbidity should preferably be below 5 NTU (GDWQ 2017). It was seen that the turbidity average values for the other hand pumps during both seasons were within the limit except for Hap 3 and 9 . The high turbidity values from Hap 3 and 9 may be due to corrosion from the facilities of this hand pump.

The average nitrate concentration in all water samples ranged from 2.3 to $53.7 \mathrm{mg} \mathrm{L}^{-1}$ (Table 1). On the whole, most of the hand pumps are below the permissible limit $\left(50 \mathrm{mg} \mathrm{L}^{-1}\right)$ by WHO guideline apart from Hap 6 whose nitrate content during the rainy season was higher than the acceptable limit stipulated by WHO. This may be explained by the excessive use of inorganic fertilizers onto the land agricultural which is practiced around to this hand pump. Nitrates are very soluble in water, so they migrate easily in groundwater when levels exceed the needs of the vegetation. The toxicity of nitrates results from their reduction to nitrites and the formation of methemoglobin on the one hand and their possible contribution to the endogenous synthesis of $\mathrm{N}$-nitroso compounds on the other hand (Tamme et al. 2009). Infant methemoglobinemia is the only health effect that has been associated unequivocally to excessive exposure to nitrates by drinking water (Karu et al. 2013). Thus, consumption of this water should be prohibited to pregnant women and infants to prevent methemoglobinemia.

Phosphates originate to the domestic waste product such as human urine and detergents. The intensive agricultural practices via soil erosion can also be a source of phosphates in the water (Kachi et al. 2015). The phosphate content of the samples had a range of 0.06 to $1.99 \mathrm{mg} \mathrm{L}^{-1}$ for both seasons, and the highest average value was observed in the rainy season. This confirms the hypothesis of the infiltration of phosphates ensuing basically from the soil modification by chemical beneath precipitation conditions. 


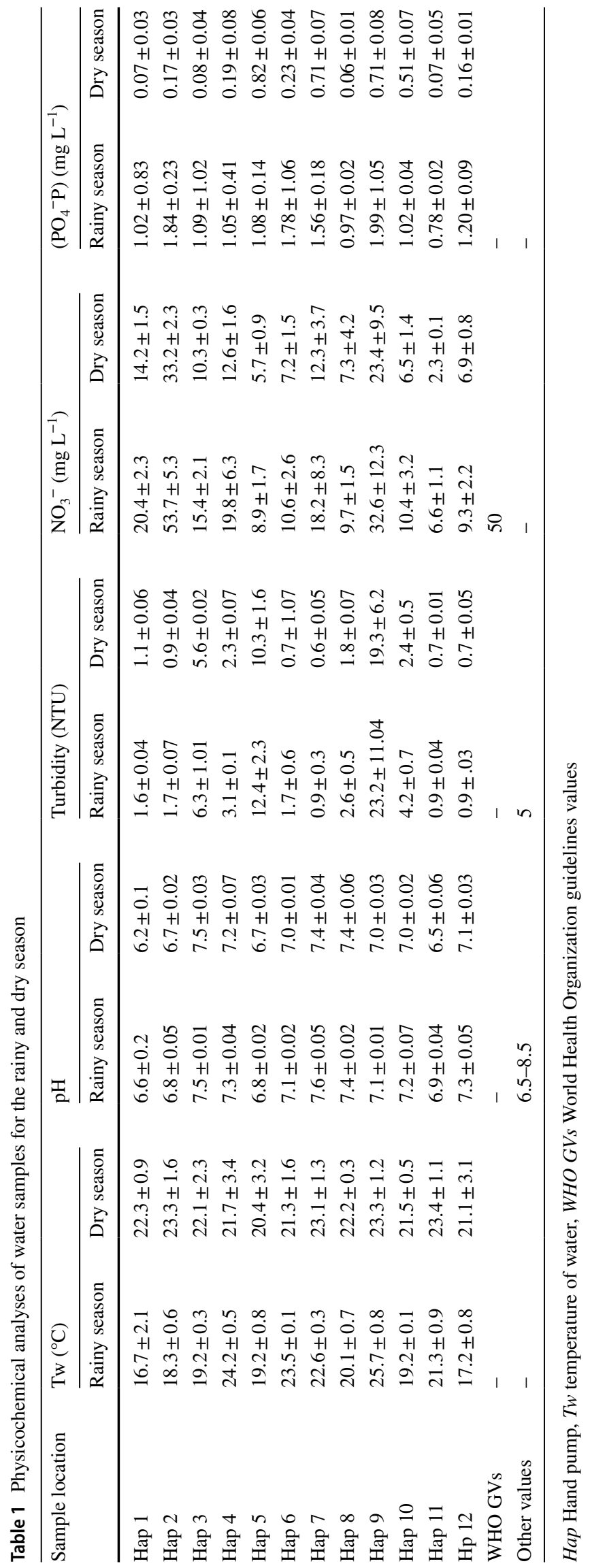


Also, the significant releases of domestic wastewater extremely charged with phosphate constituents around the hand pumps could be a contributory factor.

\section{Bacteriological analyses}

Total coliforms are considered indicators of the microbial quality of water because they can be indirectly associated with fecal pollution. The relevance of this group as an indicator is that its the presence in the waters also indicate the presence of others pathogenic organisms. Total coliforms count in the hand pump waters varied between $<1$ and $18.6 \mathrm{cfu} / 100 \mathrm{~mL}$ during the dry season, whereas in the rainy season, the values varied from 6.6 to $685.3 \mathrm{cfu} / 100 \mathrm{~mL}$ (Table 2). The values of total coliforms from the same sampling site were all higher in the rainy season than that in the dry season. It worth noticed that except for Hap 9 and 12 in the dry season, all the water samples from the remaining hand pumps were grossly below the WHO GDWQ stipulated limit of $<10 \mathrm{cfu} / 100 \mathrm{~mL}$. Additionally, except for two hand pumps water samples (Hap8, Hap10) collected during the rainy season, all the remaining were well beyond the WHO GDWQ. The high contamination of water by total coliforms during the rainy season could be not only due to the vicinity of some hand pumps with pit latrines but also to bad sanitary completion of hand pumps leading the pollutants of groundwater. Also, total coliforms could be from environmental sources, namely soils or biofilms (William 2014).

In spite of the fact that majority of the data on the profundity of the sampled hand pumps might have been not available, an additional could be allowed reason for microbial

Table 2 Microbial Analysis of hand pump water samples

\begin{tabular}{lll}
\hline Water point & \multicolumn{2}{l}{ Total coliform count $(\mathrm{cfu} / 100 \mathrm{~mL})$} \\
\cline { 2 - 3 } & Dry season & Rainy season \\
\hline Hap 1 & 1.0 & 17.2 \\
Hap 2 & 3.0 & 125.7 \\
Hap 3 & $<1$ & 21.3 \\
Hap 4 & 3.6 & 421.1 \\
Hap 5 & $<1$ & 115.2 \\
Hap 6 & 4.0 & 541.3 \\
Hap7 & 2.0 & 69.5 \\
Hap 8 & $<1$ & 6.6 \\
Hap 9 & 18.6 & 685.3 \\
Hap 10 & 1.0 & 9.1 \\
Hap 11 & $<1$ & 82.7 \\
Hap 12 & 11.6 & 397.8 \\
WHO Gvs & $\leq 10 \mathrm{cfu} / 100 \mathrm{~mL}$ & \\
Other values & $\leq 10 \mathrm{cfu} / 100 \mathrm{~mL}$ & \\
\hline
\end{tabular}

Hap Hand pump, WHO GVs World Health Organization guidelines values

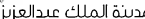

KACST Ka contamination may be that profundity of the borehole (Thivya et al. 2014; Seth et al. 2014). Lowest level profundity of a hand pump is $40 \mathrm{~m}$ such that pollutant from sources of surface is eliminated within the first $30 \mathrm{~m}$ when groundwater passes through saturated sand and non-fissured rock. In non-saturated zone, close to $40 \mathrm{~m}$ might be fundamental with purify groundwater. Yet, in fractured aquifer, pollutants can speedily pass through the non-saturated zone to the water table (Seth et al. 2014). As groundwater flows through sediment metals from various sources might be dissolved and may later be in elevated concentrations in the groundwater (Moyo 2013). Hence, hand pumps must be located at recommended safe distances in order to prevent potential contaminants (Moyo 2013).

\section{Detection of the Fecal bacteria and Total coliforms}

The overall presumable isolates from membrane-fecal coliforms agar have been put through to prelude identification assay, and findings are presented in Table 3. Indeed, out of 21 isolates, eleven are Gram-negative rods (nev rod) and eight are Gram-negative cocci (nev cocci). Furthermore, out of eleven nev rod-shaped bacteria, nine have been capable of brewing the carbohydrates within the triple sugar iron milieu. Consequently, hydrogen sulfide gas was generated by only three of these isolates which are heavily typical of Salmonella strains. Overall, ten of rod-shaped isolates have been capable of using citrate and three of those generated gas. Based on the biochemical profiles, various bacterial isolates of the Enterobacteriaceae were identified, namely Escherichia coli (7/21), Salmonella sp. (3/21) and Klebsiella sp. (1/21). However, certain of the isolates generated unknown profiles (Un.p).

Table 4 indicates the findings of the preliminary identification assays of the isolates from m-ENDO agar. It was observed that eight of the isolates are nev rods, whereas three are positive rods (pov rods). Six of the nev rod-shaped isolates partly used carbohydrates in the triple sugar iron agar; however, no one generated gas. It was noticed that three of those isolates generated $\mathrm{H}_{2} \mathrm{~S}$ gas. Total of the isolates from Endo's medium agar have not generated gas from citrate agar of Simmon, but just five have been capable of totally using citrate. The identities of the isolates from Endo's medium have been established according to the biochemical profiles, and the bacterial isolates majority were $E$. coli (8/21), Salmonella sp. (2/21) and Klebsiella sp. (1/21). Additionally, unknown profiles have also been produced by certain isolates.

The identification of the bacterial isolates within the hand pump water destined to human consumption was undesirable, as they may bring about serious human health issues. Indeed, among the bacteria isolated a well-specified pathogen and indicator in the group Enterobacteriaceae is the E. coli. This 
Table 3 The preliminary identification assay findings for presumptive coliform microorganism isolates with membrane-fecal coliforms agar and biochemical profiles

\begin{tabular}{|c|c|c|c|c|c|c|c|c|c|}
\hline \multirow[t]{2}{*}{ Isolate code } & \multirow[t]{2}{*}{ Gram staining } & \multicolumn{3}{|c|}{ Triple sugar iron } & \multirow[t]{2}{*}{$\mathrm{H}_{2} \mathrm{~S}$} & \multicolumn{3}{|c|}{ Citrate utilization } & \multirow[t]{2}{*}{ Biochemical profiles } \\
\hline & & Butt & Slant & Gas & & Butt & Slant & Gas & \\
\hline $\mathrm{HA}_{1}$ & nev rod & pov & pov & pov & nev & nev & pov & pov & E-coli \\
\hline $\mathrm{HA}_{2}$ & nev rod & pov & pov & nev & nev & nev & pov & nev & E-coli \\
\hline $\mathrm{HA}_{3}$ & nev rod & pov & pov & nev & nev & pov & pov & nev & Salmonella species \\
\hline $\mathrm{HB}_{1}$ & nev cocci & pov & nev & nev & nev & nev & pov & nev & Un.p \\
\hline $\mathrm{HB}_{2}$ & nev rod & pov & pov & pov & nev & nev & pov & nev & Salmonella species \\
\hline $\mathrm{HB}_{3}$ & nev rod & pov & pov & nev & nev & nev & pov & nev & E-coli \\
\hline $\mathrm{HC}_{1}$ & nev rod & pov & nev & nev & pov & nev & pov & pov & E-coli \\
\hline $\mathrm{HC}_{2}$ & nev cocci & pov & nev & nev & nev & pov & pov & nev & Un.p \\
\hline $\mathrm{HC}_{3}$ & nev rod & pov & nev & nev & nev & nev & pov & pov & $E$-coli \\
\hline $\mathrm{HD}_{1}$ & nev cocci & nev & nev & nev & nev & pov & pov & nev & Un.p \\
\hline $\mathrm{HD}_{2}$ & pov cocci & nev & nev & nev & pov & nev & pov & nev & Un.p \\
\hline $\mathrm{HD}_{3}$ & nev rod & pov & pov & nev & nev & nev & pov & nev & $E$-coli \\
\hline $\mathrm{HE}_{1}$ & nev cocci & nev & nev & nev & nev & pov & pov & nev & Un.p \\
\hline $\mathrm{HE}_{2}$ & nev cocci & pov & nev & nev & nev & nev & pov & nev & Un.p \\
\hline $\mathrm{HE}_{3}$ & pov cocci & nev & nev & nev & nev & pov & pov & nev & Un.p \\
\hline $\mathrm{HF}_{1}$ & nev rod & pov & pov & nev & nev & nev & pov & nev & Klebsiella species \\
\hline $\mathrm{HF}_{2}$ & nev rod & pov & pov & nev & pov & nev & pov & nev & Salmonella species \\
\hline $\mathrm{HF}_{3}$ & nev cocci & pov & nev & nev & nev & nev & pov & nev & Un.p \\
\hline $\mathrm{HG}_{1}$ & nev cocci & pov & nev & nev & nev & pov & pov & nev & Un.p \\
\hline $\mathrm{HG}_{2}$ & nev cocci & pov & nev & nev & nev & pov & pov & nev & Un.p \\
\hline $\mathrm{HG}_{3}$ & nev rod & pov & pov & nev & pov & nev & pov & nev & E-coli \\
\hline
\end{tabular}

nev rod Gram-negative rod, nev cocci Gram-negative cocci, Un.p unknown profile, E- coli: Escherichia coli, pov positive, nev negative bacteriai has been most often isolated from membrane-fecal coliforms agar (7/21) and Endo's medium (8/21), respectively. This is of a high significance for health and demands for remedial attention in the water supply. Indeed, E.coli contributes to increasing the prevalence of enteric ailments like traveler's diarrhoea and other kinds of looseness of the bowels (Kamanula et al. 2014). It was confirmed that bacteria belonging to the group Enterobacteriaceae arise exclusively from the intestines of warm-blooded animals, including humans, and their presence is the most accurate indicator of fecal contamination (El Haissoufi et al. 2011). Nevertheless, it does not identify the precise source of fecal matters. There are several sources: manure, grazing, septic tanks, latrine and other sources, such as wildlife. According to our surveys of the hand pumps in the sites studied, we noticed the existence of manure, septic tanks and pit latrines and waste of all kinds on the land around of some hand pumps. In addition, several animals were observed near the sampling sites (dogs, goats, donkeys, oxen, chickens), which represents a fairly significant contamination potential. All the hand pumps were approximately within a $50 \mathrm{~m}$ or less radius from pit latrines, refuse tips and other social amenities.

\section{Conclusions}

This study investigated the physicochemical and bacteriological quality of some hand pump water in Pelengana commune. It was discovered that the water of these hand pumps was vulnerable to physicochemical and bacteriological contamination. Findings illustrated that contamination varied with seasons, the highest levels have been observed in the rainy season. However, it was noticed that seasonal variation (from dry to rainy season), with the exception of the microorganism quality of the hand pump water that worsens considerably throughout the rainy season, did not have an effect on the quality of water. Consequently, it is worth noting that the hand pumps examined in this study are subject to contamination thanks both to agricultural activities practiced in the vicinity of hand pumps and poor hygienic practices at those sites. However, it is suggested that the villagers need to be educated on the importance of maintaining clean and hygienic environment around the vicinity of the hand pumps to ensure the safety of water from such sources. Additionally, adequate treatment should be effected in accordance with seasonal variation compared with the major bacteriological and physicochemical parameters. 
Table 4 The preliminary identification assay findings for presumptive coliform microorganism isolates with Endo's medium agar and biochemical profiles

\begin{tabular}{|c|c|c|c|c|c|c|c|c|c|}
\hline \multirow[t]{2}{*}{ Isolate code } & \multirow[t]{2}{*}{ Gram staining } & \multicolumn{3}{|c|}{ Triple sugar iron } & \multirow[t]{2}{*}{$\mathrm{H}_{2} \mathrm{~S}$} & \multicolumn{3}{|c|}{ Citrate utilization } & \multirow[t]{2}{*}{ Biochemical profiles } \\
\hline & & Butt & Slant & Gas & & Butt & Slant & Gas & \\
\hline $\mathrm{HA}_{1}$ & nev rod & nev & nev & nev & pov & nev & pov & nev & Salmonella species \\
\hline $\mathrm{HA}_{2}$ & nev cocci & pov & nev & nev & nev & nev & pov & nev & Un.p \\
\hline $\mathrm{HA}_{3}$ & nev rod & pov & nev & nev & nev & pov & pov & nev & E-coli \\
\hline $\mathrm{HB}_{1}$ & nev cocci & pov & nev & nev & nev & nev & pov & nev & Un.p \\
\hline $\mathrm{HB}_{2}$ & nev cocci & pov & pov & nev & nev & nev & pov & nev & Un.p \\
\hline $\mathrm{HB}_{3}$ & nev rod & pov & pov & nev & nev & nev & pov & nev & E-coli \\
\hline $\mathrm{HC}_{1}$ & nev rod & pov & nev & nev & pov & nev & pov & nev & E-coli \\
\hline $\mathrm{HC}_{2}$ & nev rod & pov & nev & nev & nev & pov & pov & nev & E-coli \\
\hline $\mathrm{HC}_{3}$ & nev cocci & pov & nev & nev & nev & nev & pov & nev & Un.p \\
\hline $\mathrm{HD}_{1}$ & nev cocci & nev & nev & nev & nev & pov & pov & nev & Un.p \\
\hline $\mathrm{HD}_{2}$ & pov cocci & nev & nev & nev & nev & nev & pov & nev & Un.p \\
\hline $\mathrm{HD}_{3}$ & nev rod & pov & pov & nev & pov & nev & pov & nev & E-coli \\
\hline $\mathrm{HE}_{1}$ & nev rod & nev & nev & nev & nev & pov & pov & nev & Klebsiella species \\
\hline $\mathrm{HE}_{2}$ & nev rod & pov & nev & nev & nev & nev & pov & nev & E-coli \\
\hline $\mathrm{HE}_{3}$ & nev cocci & nev & nev & nev & pov & pov & pov & nev & Un.p \\
\hline $\mathrm{HF}_{1}$ & pov rod & pov & pov & nev & nev & nev & pov & nev & E-coli \\
\hline $\mathrm{HF}_{2}$ & nev cocci & pov & pov & nev & pov & nev & pov & nev & Un.p \\
\hline $\mathrm{HF}_{3}$ & nev cocci & pov & nev & nev & nev & nev & pov & nev & Un.p \\
\hline $\mathrm{HG}_{1}$ & pov rod & nev & nev & nev & pov & pov & pov & nev & Salmonella species \\
\hline $\mathrm{HG}_{2}$ & pov rod & pov & nev & nev & nev & pov & pov & nev & E-coli \\
\hline $\mathrm{HG}_{3}$ & nev cocci & pov & pov & pov & nev & nev & pov & nev & Un.p \\
\hline
\end{tabular}

nev rod Gram-negative rods, pov rod gram-positive rod, nev cocci gram-negative cocci, Un.p unknown profile, E-coli: Escherichia coli, pov positive, nev negative
Acknowledgments The authors acknowledge the central Water Quality Laboratory (SOMAGEP) personnel for their support in laboratory analyses. Authors would also like to thank the villagers for wholehearted participation in this study.

Open Access This article is licensed under a Creative Commons Attribution 4.0 International License, which permits use, sharing, adaptation, distribution and reproduction in any medium or format, as long as you give appropriate credit to the original author(s) and the source, provide a link to the Creative Commons licence, and indicate if changes were made. The images or other third party material in this article are included in the article's Creative Commons licence, unless indicated otherwise in a credit line to the material. If material is not included in the article's Creative Commons licence and your intended use is not permitted by statutory regulation or exceeds the permitted use, you will need to obtain permission directly from the copyright holder. To view a copy of this licence, visit http://creativecommons.org/licenses/by/4.0/.

\section{References}

APHA (1992) Standard Methods for the Examination of Water and Wastewater, 18th Ed. American Public Health Association and Water Environmental Foundation EPS Group, Inc., Maryland, USA. pp 2-55, 129-131

Bello OO, Osho A, Bankole SA, Bello TK (2013) Bacteriological and physicochemical analyses of borehole and well water sources in Ijebu-Ode, Southwestern Nigeria. Int J Pharm Biol Sci 8:18-25
CPS/MS, DNSI, MEIC et Macro International Inc. (2006) Enquête Démographique et de Santé Du Mali

Degbey C, Makoutode M, Agueh V, Dramaix M, De Brouwer C (2011) Facteurs Associés à La Qualité de l'eau de Puits et Prévalence Des Maladies Hydriques Dans La Commune d'Abomey-Calavi (Bénin). Sante 21(1):47-55. https://doi. org/10.1684/san.2011.0238

El Haissoufi H, Berrada S, Merzouki M, Aabouch M, Bennani L, Benlemlih M, Idrir M, Zanibou A, Bennis Y, El Ouali Lalami A (2011) Pollution Des Eaux De Puits De Certains Quartiers de La Ville de Fes, Maroc. Rev Microbiol Ind San et Environn 5(1):37-68

GDWQ (2017) Guidelines for drinking-water quality, 4th edn. Incorporating the first addendum. World Health Organization, Geneva

Harvey PA (2004) Borehole sustainability in Rural Africa: an analysis of routine field data. In: 30th WEDC international conference, Vientiane, Lao PDR. People-Centred Approaches to Water and Environmental Sanitation

Healy JM, Profitós AM, Lee S, Garabed R, Moritz M, Piperata B, Tien J, Bisesi M, Lee J (2014) Muddying the waters: a new area of concern for drinking water contamination in cameroon. Int $\mathrm{J}$ Environ Res Public Health 11:12454-12472

Ho KC, Chow YL, Yau JTS (2003) Chemical and microbiological qualities of the east river (Dongjiang) water, with particular reference to drinking water supply in Hong Kong. Chemosphere 52:1441-1450

Ikemoto Y, Teraguchi M, Kaneene Y (2002) Plasma level of nitrate in congenital heart disease: comparison with healthy children. Pediatr Cardiol 23:132-136 
Iyasele JU, Idiata DJ (2012) Determining the borehole water quality in Edo South and Edo North Areas of Edo State. Res J Eng Appl Sci 1(4):209-213

Kachi N, Kachi S, Bousnoubra H (2015) Evaluation of the physico-chemical and bacteriological quality of surface waters in Guelma Basin, Algeria. Int J Environ Monit Anal 3(5):238-244

Kamanula JF, Zambasa OJ, Masamba WRL (2014) Quality of drinking water and cholera prevalence in Ndirande Township, City of Blantyre, Malawi. Phys Chem Earth 72-75:61-67. https://doi. org/10.1016/j.pce.2014.09.001

Karu E, Ziyok I, Amanki ED (2013) Physicochemical analysis of ground water of selected Areas of Dass and Ganjuwa local government areas, Bauchi State, Nigeria. Sci Educ Publ 1:73-79

Mor S, Ravindra K, Dahiya RP, Chandra A (2006) Leachate characterization and assessment of groundwater pollution near municipal solid waste landfill site. Environ Monit Assess 118:435-456

Moyo NAG (2013) An analysis of the chemical and microbiological quality of ground water from boreholes and shallow wells in Zimbabwe. Phys Chem Earth 66:27-32. https://doi. org/10.1016/j.pce.2013.06.003

Olajire AA, Imeokparia FE (2001) Water quality assessment of Osun river: studies on inorganic nutrients. Environ Monit Assess 69:17-22

Palamuleni L, Mercy A (2015) Physico-chemical and microbial analysis of selected borehole water in Mahikeng, South Africa. Int J Environ Res Public Health 12:8619-8630

Prasad BG, Narayana TS (2004) Subsurface water quality of different sampling stations with some selected parameters at Machilipatnam town. Nat Environ Pollut Technol 3(1):47-50

Raihan F, Alam JB (2008) Assessment of groundwater quality in Sunamganj of Bangladesh. Iran J Environ Health Sci Eng 5(3):155-166

RGPH. (2009) 4 Ème Recensement General de La Population et de l'Habitat Du Mali (RGPH-2009) Analyse Des Resultats Definitifs Theme 2

Sabhapandit P, Saikia P (2010) Interpretation of ground and surface water quality using principal component analysis in Gohpur sub-division of Sonitpur district, Assam, India. Int J Chem Sci 8(3):1523-1536

Seth ON, Tagbor TA, Bernard O (2014) Assessment of chemical quality of groundwater over some rock types in Ashanti region, Ghana. Am J Sci Ind Res 5:1-6

Shittu OB, Olaitan JO, Amusa T (2008) Physico-chemical analysis of water used for drinking and swimming purposes in Abeokuta, Nigeria. Afr J Biomed Res 11:285-290

Tamme T, Reinik M, Roasto M (2009) Nitrates and nitrites in vegetables: occurrence and health risks. In: Watson RR, Preedy VR (eds) Bioactive foods promoting health: fruits and vegetables. Academic Press, Salt Lake City, pp 307-321

Thivya C, Chidambaram S, Thilagavathi R, Nepolian M, Adithya VS (2014) Evaluation of drinking water quality index (DWQI) and its seasonal variations in hard rock aquifers of Madurai district, Tamilnadu. Int J Adv Geosci 2:48-52

USEPA (2009) Method 1603: Escherichia coli (E. coli) in water by membrane filtration using modified membrane-Thermotolerant Escherichia coli Agar (Modified mTEC); US Environmental Protection Agency office of water (4303 T): Washington, DC, USA, 42

WHO (2011) Guidelines for drinking water quality, 4th edn. WHO Press, Geneva

William L (2014) Assessment of borehole water quality and consumption in Yei Thesis in partial fulfillment of the requirements for the degree Master of science in environment and natural resources of Makerere University, South Sudan, pp 1-125

World Health Organization (WHO) (2008) Guidelines for Drinking Water Quality, Incorporating 1st and 2nd Addenda, Vol. 1, Recommendations, 3rd Ed.’WHO: Geneva, Switzerland

Publisher's Note Springer Nature remains neutral with regard to jurisdictional claims in published maps and institutional affiliations. 